\title{
common mental disorders, subthreshold symptoms and disability: longitudinal study
}

Dheeraj Rai, Petros Skapinakis, Nicola Wiles, Glyn Lewis and Ricardo Araya

\section{Summary}

In a representative sample of the UK population we found that common mental disorders (as a group and in ICD-10 diagnostic categories) and subthreshold psychiatric symptoms at baseline were both independently associated with new-onset functional disability and significant days lost from work at 18-month follow-up. Subthreshold symptoms contributed to almost half the aggregate burden of functional disability and over 32 million days lost from work in the year preceding the study. Leaving these symptoms unaccounted for in surveys may lead to gross underestimation of disability related to psychiatric morbidity.

\section{Declaration of interest}

None.
The association between psychiatric morbidity and subsequent disability may have been underestimated ${ }^{1,2}$ because disability related to subthreshold symptoms is not included in calculations. Previous longitudinal studies on this subject have concentrated mainly on depression and its subthreshold presentations, ${ }^{1,3}$ and cross-sectional studies cannot ascertain the direction of causality. Furthermore, disability related to anxiety-based disorders and mixed anxiety/depression is sparsely documented. ${ }^{4}$ We studied the relative contribution of subthreshold psychiatric symptoms and common mental disorders ${ }^{5}$ at baseline as predictors of newonset functional disability and days lost from work at 18 months follow-up in the UK population.

\section{Method}

We used data from the longitudinal subset of the 2000 UK Psychiatric Morbidity Survey (details available elsewhere). ${ }^{6}$ Briefly, 8580 adults representative of the UK population participated in face-to-face interviews at baseline $\left(T_{1}\right)$ in 2000. A representative subsample $(n=2406)$ was followed up 18 months later $\left(T_{2}\right)$. Ethical approval was granted by the Multi-centre Research Ethics Committee in England.

Psychiatric morbidity was assessed using the revised Clinical Interview Schedule (CIS-R). ${ }^{7}$ A CIS-R score of $\geqslant 12$ indicates the presence of a common mental disorder and algorithms allow identification of ICD-10 diagnoses of depression, anxiety-based disorders (phobias, generalised anxiety disorder, panic disorder and obsessive-compulsive disorder) and mixed anxiety/depression. We defined three main exposure groups: no common mental disorders (CIS-R score $<6$ and no ICD-10 diagnosis); subthreshold psychiatric symptoms (CIS-R score 6-11 and no ICD-10 diagnosis); and common mental disorders (CIS-R score $\geqslant 12$ or an ICD-10 diagnosis).

Functional disability was studied using seven domains of activities of daily living ${ }^{6,8}$ including personal care, using transport, medical care, household activities, practical activities, dealing with paperwork and managing money (see online supplement). Those employed were asked to report the number of days they had been off sick from work in the past year. We estimated mean days lost from work in each group of psychiatric morbidity. We also added the number of days reported lost in the past year by respondents in each category of psychiatric morbidity and extrapolated them to the UK population using weights.

For regression analyses we studied two outcomes. First, new-onset functional disability (defined as report of new activities of daily living difficulties in any domain at $T_{2}$ ) in a cohort of people with no activities of daily living difficulties at $T_{1}$ $(n=1573)$. Second, 1 or more days, and $>14$ days lost from work in the past year in a cohort employed at both waves $(n=1317)$.

Logistic regression was used to estimate the association of psychiatric morbidity and the outcomes, while adjusting for potential confounders (Table 1). Analyses were conducted using svy commands in Stata I/C v.10.1 (Windows). Probability weights were used to account for the stratified sampling and non-response. ${ }^{6}$ Population attributable-risk fractions were calculated using the aflogit procedure.

\section{Results}

Among people with no functional disability at baseline $(n=1573)$, $15.2 \%$ had subthreshold symptoms and $11.9 \%$ a common mental disorder. In total, $60 \%$ of those with common mental disorders had mixed anxiety/depression, $28.6 \%$ had an ICD-10 anxietybased disorder and $11.4 \%$ a depressive episode.

During follow-up, $14.8 \%$ of participants with common mental disorders at baseline developed a new functional disability, compared with $12.6 \%$ of those with subthreshold symptoms and $7.7 \%$ of those with no common mental disorder (Fig. DS1). A graded relationship was also observed in mean days lost from work; those with no common mental disorders at baseline missed 4.1 days (s.d. $=1.9$ ), those with subthreshold symptoms 7.6 days $($ s.d. $=2.5)$ and those with a common mental disorder 13.2 days (s.d. =4.0). An estimated 148.3 million days were lost from work in the year preceding $T_{2}$ when extrapolating results to the UK population. These comprised: no common mental disorders 70.3 million days (95\% CI 37.3-103.0), subthreshold symptoms 32.4 million days (95\% CI 21.6-43.2), mixed anxiety/depression 25.3 million days (95\% CI 16.0-34.5), ICD-10 anxiety-based disorders 10.9 million days (95\% CI 3.3-18.5) and ICD-10 depression 9.4 million days (95\% CI 1.1-17.7).

Individuals with baseline subthreshold symptoms or common mental disorders were both twice as likely to report a new-onset functional disability at $T_{2}$ compared with those with no common mental disorders (Table 1). A non-linear relationship was observed between subthreshold symptoms and work days lost. There was no association between subthreshold symptoms and single-day work absences (adjusted odds ratio $(\mathrm{OR})=1.1,95 \%$ CI $0.8-1.7)$ but these individuals were two times more likely to report absences lasting over 14 days (Table 1.) Common mental disorders, by contrast, were associated with over a twofold increase in odds for both these outcomes (adjusted OR for 1 day lost 2.2, 95\% CI 1.5-3.1; for 14-days lost $\mathrm{OR}=2.9,95 \%$ 
Table 1 Relationship between baseline psychiatric morbidity and new-onset functional disability and $>14$ days off work at 18-month follow-up: weighted logistic regression analyses and population attributable fractions

\begin{tabular}{|c|c|c|c|c|c|c|}
\hline & \multicolumn{3}{|c|}{$\begin{array}{l}\text { Onset of functional disability at } T_{2} \text { (in cohort } \\
\text { with no functional disability at } T_{1}, n=1573 \text { ) }\end{array}$} & \multicolumn{3}{|c|}{$\begin{array}{l}>14 \text { days off work in past year at } T_{2} \\
\text { (in cohort employed at both waves, } n=1317 \text { ) }\end{array}$} \\
\hline & Crude OR $(95 \% \mathrm{Cl})$ & Adjusted OR $(95 \% \mathrm{Cl})$ & $\mathrm{PAF}, \%^{\mathrm{b}}$ & Crude OR $(95 \% \mathrm{Cl})$ & Adjusted $\mathrm{OR}^{\mathrm{a}}(95 \% \mathrm{Cl})$ & PAF, ${ }^{\mathrm{b}}$ \\
\hline No common mental disorders & 1 & 1 & & 1 & 1 & \\
\hline Subthreshold symptoms & $1.7(1.1-2.7)^{\star}$ & $2.2(1.3-3.6)^{* *}$ & 11.1 & $2.3(1.3-4.2)^{\star \star}$ & $1.9(1.1-3.5)^{\star}$ & 14.4 \\
\hline Common mental disorders & $2.1(1.3-3.3)^{* *}$ & $2.5(1.5-4.3)^{* *}$ & 12.7 & $3.6(2.1-6.3)^{\star * *}$ & $2.9(1.6-5.2)^{\star *}$ & 25.6 \\
\hline Mixed anxiety/depression & $1.7(1.0-3.0)$ & $2.2(1.1-4.3)^{*}$ & 4.4 & $3.7(2.0-6.8)^{\star *}$ & $2.9(1.5-5.6)^{\star *}$ & 14.4 \\
\hline ICD-10 anxiety-based disorder & $2.7(1.5-4.8)^{\star *}$ & $2.9(1.5-5.6)^{\star \star}$ & 5.3 & $2.7(1.2-6.1)^{\star}$ & $2.3(0.9-5.5)$ & 4.1 \\
\hline \multirow[t]{2}{*}{ ICD-10 depression } & $2.9(1.3-6.6)^{*}$ & $3.3(1.3-8.1)^{*}$ & 3.0 & $5.3(2.2-12.7)^{\star *}$ & $4.6(1.7-11.9)^{* *}$ & 7.1 \\
\hline & & & $23.8^{c}$ & & & $40.00^{C}$ \\
\hline \multicolumn{7}{|c|}{$\begin{array}{l}\text { a. Adjusted odds ratios (OR) and } 95 \% \text { confidence intervals derived by models adjusted for age, gender, marital status, ethnicity, social class, employment status, highest educationa } \\
\text { qualification, area type, tenure of housing, size of primary support group, life events at } T_{1} \text { and between } T_{1} \text { and } T_{2} \text {, current smoking, past year illicit drug use, Alcohol Use Disorders } \\
\text { Identification and Treatment (AUDIT) score, baseline psychiatric treatment (medication or psychotherapy) and self-reported physical complaints. } \\
\text { b. Population attributable-risk fractions (PAFs) \% derived from the adjusted unweighted logistic regression models. The PAFs denote the proportion of an outcome in the population } \\
\text { that would be prevented if the exposure were completely removed assuming the association was causal and all confounding accounted for. } \\
\text { C. Aggregated PAF. } \\
{ }^{*} P<0.05, \star \star P<0.01 \text {. }\end{array}$} \\
\hline
\end{tabular}

CI 1.6-5.2.) Population attributable-risk fractions for subthreshold symptoms explained a much greater proportion of new-onset functional disability (11.1\%) than ICD-10 depression $(3.0 \%)$ or anxiety-based disorders $(5.3 \%)$.

\section{Discussion}

We found that both subthreshold symptoms and common mental disorders pose a substantial risk of functional disability and absence from work, even after accounting for potential confounders. Almost half the aggregate burden of new-onset functional disability in the population as a result of psychiatric morbidity could be attributed to subthreshold symptoms. Almost two-thirds of the future disability attributable to psychiatric symptoms in the population may be missed if analyses are restricted to individuals with anxiety and depressive disorders.

Our results add to previous findings that disability rises in increments with increasing psychiatric symptom load, ${ }^{1,3}$ not just for depression but for the entire spectrum of common mental disorders. We found that the largest proportion of disability even in the common mental disorders group was contributed by mixed anxiety/depression that is itself often considered a subthreshold category. ${ }^{4}$ We highlight that the aggregate costs of psychiatric symptoms to society may be grossly underestimated when studying specific psychiatric diagnoses in isolation.

The use of a structured psychiatric interview, a large representative sample and prospective design are strengths of this study. Limitations include attrition in the two waves leading to an overall 56\% response rate, although we accounted for non-response using probability weights. Data collection at two time points, with little knowledge of the intervening period may have led to some random misclassification. Finally, our broad definition of functional disability may overestimate disability; and the possibility of recall bias of reported work days lost cannot be excluded.

The importance of subthreshold symptoms should not be underestimated. However, this should not be interpreted as if we suggest the creation of a new diagnostic category. Since subthreshold symptoms are likely to be on the same continuum as common mental disorders ${ }^{3,10}$ rather than distinct disorders, adding dimensional approaches to supplement categorical diagnostic systems may help improve their recognition. ${ }^{11}$ Development of strategies to identify and manage these problems may reduce future disability associated with them, generating significant societal savings.
Dheeraj Rai, MBBS, MRCPsych, Academic Unit of Psychiatry, University of Bristol, Bristol, UK; Petros Skapinakis, MD, MPH, PhD, Academic Unit of Psychiatry, University of Bristol, UK, and Department of Psychiatry, University of Ioannina Schoo of Medicine, Greece; Nicola Wiles, BSC, PhD, Glyn Lewis, FRCPsych, PhD, Ricardo Araya, MRCPsych, PhD, Academic Unit of Psychiatry, University of Bristol, Bristol, UK

Correspondence: Dr D. Rai, MBBS, MRCPsych, Academic Unit of Psychiatry, University of Bristol, Cotham House, Cotham Hill, Bristol BS6 6JL, UK. Email: dheeraj.rai@bristol.ac.uk

First received 26 Feb 2010, final revision 27 Apr 2010, accepted 24 Jun 2010

\section{Funding}

Data collection was funded by the Department of Health and the Scottish Executive Health Department.

\section{Acknowledgements}

We thank the Office of National Statistics for initial design work, fieldwork and data preparation.

\section{References}

1 Broadhead WE, Blazer DG, George LK, Tse CK. Depression, disability days, and days lost from work in a prospective epidemiologic survey. JAMA 1990; 264: 2524-8.

2 Mykletun A, Overland S, Dahl AA, Krokstad S, Bjerkeset O, Glozier $\mathrm{N}$, et al. A population-based cohort study of the effect of common mental disorders on disability pension awards. Am J Psychiatry 2006; 163: 1412-8.

3 Judd LL, Akiskal HS, Zeller PJ, Paulus M, Leon AC, Maser JD, et al. Psychosocial disability during the long-term course of unipolar major depressive disorder. Arch Gen Psychiatry 2000; 57: 375-80.

4 Das-Munshi J, Goldberg D, Bebbington PE, Bhugra DK, Brugha TS, Dewey ME, et al. Public health significance of mixed anxiety and depression: beyond current classification. Br J Psychiatry 2008; 192: 171-7.

5 World Health Organization. The ICD-10 Classification of Mental and Behavioural Disorders: Clinical Descriptions and Diagnostic Guidelines. WHO, 1992.

6 Singleton N, Lewis G. Better or Worse: A Longitudinal Study of the Mental Health of Adults Living in Private Households in Great Britain. TSO (The Stationery Office), 2003.

7 Lewis G, Pelosi AJ, Araya R, Dunn G. Measuring psychiatric disorder in the community: a standardized assessment for use by lay interviewers. Psychol Med 1992; 22: 465-86.

8 Brewin CR, Wing JK, Mangen SP, Brugha TS, MacCarthy B. Principles and practice of measuring needs in the long-term mentally ill: the MRC needs for care assessment. Psychol Med 1987; 17: 971-81.

9 Saunders JB, Aasland OG, Babor TF, de la Fuente JR, Grant M. Development of the Alcohol Use Disorders Identification Test (AUDIT): WHO collaborative project on early detection of persons with harmful alcohol consumption - II. Addiction 1993; 88: 791-804.

10 Cuijpers $P$, de GR, van DS. Minor depression: risk profiles, functional disability, health care use and risk of developing major depression. J Affect Disord 2004; 79: 71-9.

11 Helzer JE, Kraemer HC, Krueger RF. The feasibility and need for dimensional psychiatric diagnoses. Psychol Med 2006; 36: 1671-80. 